\title{
Higiene e a reinvenção da dietética: a economia política da vida na medicina luso-brasileira da passagem do século XVIII para o XIX
}

Hygiene and the reinvention of dietetics: the political economy of life in LusoBrazilian medicine from the 18th to the 19th century

\section{Gabriel Pugliese}

\section{(2) OpenEdition Journals}

\section{Edição electrónica}

URL: https://journals.openedition.org/aa/4974

DOI: 10.4000/aa.4974

ISSN: 2357-738X

\section{Editora}

Programa de Pós-Graduação em Antropologia Social (UnB)

\section{Edição impressa}

Paginação: 232-248

ISSN: 0102-4302

\section{Refêrencia eletrónica}

Gabriel Pugliese, «Higiene e a reinvenção da dietética: a economia política da vida na medicina lusobrasileira da passagem do século XVIII para o XIX», Anuário Antropológico [Online], v.45 n. 1 | 2020 , posto online no dia 27 janeiro 2020, consultado o 23 julho 2022. URL: http://journals.openedition.org/ aa/4974 ; DOI: https://doi.org/10.4000/aa.4974

\section{(c) (i) (9)}

Creative Commons - Atribuição-NãoComercial-SemDerivações 4.0 Internacional - CC BY-NC-ND 4.0 https://creativecommons.org/licenses/by-nc-nd/4.0/ 


\title{
Higiene e a reinvenção da dietética: \\ a economia política da vida na medicina \\ luso-brasileira da passagem do século XVIII para o XIX
}

Hygiene and the reinvention of dietetics: the political economy of life in Luso-Brazilian medicine from the 18th to the 19th century

DOI: https://doi.org/10.4000/aa.4974

\begin{abstract}
Gabriel Pugliese • Universidade Federal do Vale do São Francisco - Brasil
Doutor em Antropologia Social pela Universidade de São Paulo (2015) e professor na Universidade Federal do Vale do São Francisco. Membro do Krisis - laboratório de antropologia, filosofia e política do CCS/UNIVASF. Desenvolve pesquisas na área de Antropologia, com interesse nas relações históricas entre ciência, política e poder.
\end{abstract}

O objeto do presente artigo é o problema da formação histórica do saber médico da Higiene na sua relação com a nascente economia política e o modo como as técnicas dietéticas tornaram-se um importante instrumento dessa relação. O objetivo é demonstrar como a Higiene confiscou dois conjuntos de saberes, o vitalismo e o neo- hipocratismo, para responder às demandas da economia política, convertendo-se em uma "tecnologia do sujeito", que teve na dietética o seu ponto mais importante de ancoragem. Para tanto, analisa alguns documentos médico-filosóficos da virada do século XVIII para o XIX, no âmbito luso-brasileiro. Esse canteiro histórico representa um importante momento para a biopolítica, pois implica seriamente como um elemento na transformação da noção de vida e, principalmente, para o seu desdobramento ético acerca da vida que vale a pena ser vivida.
The object of this article is the problem of historical formation of Hygiene medical knowledge in relation to the emerging political economy and the way in which dietary techniques have become an important instrument of this correlation. The objective is to demonstrate how Hygiene had confiscated two sets of knowledge, vitalism and neo-Hypocratism, to respond to the demands of political economy, becoming a "technology of the subject" that had its most important point of anchorage in dietetics. To this end, it analyzes some medical-philosophical documents from the turn of the eighteenth to the nineteenth century in the Luso-Brazilian context. This historical worksite represents an important moment for biopolitics, since it seriously implies as an element in the transformation of the notion of life and especially for its ethical unfolding about life that is worth living.

Hygiene. Dietetics. Biopolitics. Life. Anthropology of health. 


\section{Nota inicial ${ }^{1}$}

Gostaria de apresentar neste artigo como a constituição do saber médico, que conhecemos como Higiene, está ligada ao cruzamento de dois conjuntos discursivos presentes nas linhas de argumentação médica no final do século XVIII: o neo-hipocratismo e o vitalismo. Esses dois saberes foram convergidos a responder, através da medicina, aos anseios da nascente economia política que ganhava força na Europa, com o avanço do liberalismo. Especialmente, porque o governo da saúde das populações apresentava-se como uma necessidade urgente para o incremento da riqueza das nações.

A ideia é demonstrar como o conjunto da medicina dietética galeno-hipocrática, de longa duração na história ocidental, transformou-se, por meio de algumas concepções vitalistas, no que passamos a compreender como Higiene. O objetivo, assim, é trazer alguma luz à formação histórica desse problema no cenário luso-brasileiro sob o prisma de algumas relações que transformaram a Higiene no acontecimento que possibilitou a entrada da dietética na ordem biopolítica. Tais canteiros históricos me parecem importantes para compreender o modo como o conceito de vida, especificamente de vida saudável, entrou no quadro geral de preocupações da "razão de Estado" e como preparou terreno para toda uma tecnologia do sujeito que encontrará nas práticas dietéticas um importante eco de sua realização.

Isso implica, é claro, aceitar as teses de Hannah Arendt (2010) e Michel Foucault (2006b, 2008a) sobre o lugar que a vida vivente ocupa na política moderna - com o objetivo de contribuir com novas direções de pesquisa -, tal como vêm sugerindo há algum tempo Rabinow e Rose (2006). Desse modo, este artigo assume uma pretensão genealógica: uma análise do passado que possa ser, ao mesmo tempo, uma crítica do presente. O que interessa para este artigo são as relações que constituem o saber médico da Higiene no mundo luso-brasileiro como um problema histórico e os elementos político-governamentais decorrentes desse acontecimento. A seleção de documentos que se segue no texto - entre os trabalhados na pesquisa maior (Pugliese, 2015) - foi feita em torno do problema que é o objeto de argumentação desse artigo. Assim, apesar de se tratar de uma pesquisa histórica, ela não tem nenhuma pretensão historiográfica ${ }^{2} \mathrm{e}$, portanto, não cabe aqui analisar em exaustão a literatura médico-filosófica do período e, tampouco, realizar uma análise do contexto histórico ${ }^{3}$.

A primeira parte do artigo explorará os elementos por meio dos quais o saber médico aspirou tornar-se uma "razão de Estado". A segunda parte problematizará como o vitalismo se tornou um importante vetor para responder as demandas dessa transformação por meio de uma atualização do conceito de vida. A terceira parte discutirá as estratégias implicadas nesse discurso médico nos termos do neo-hipocratismo, explorando as técnicas de governo de si e dos outros que se constituíram em torno da formação de um conjunto dietético, que tinham como propósito conduzir a população a um modo de vida saudável.
1 Uma prévia deste texto, que é uma reorganização da argumentação de uma parte de minha tese de doutorado, foi apresentada na XIII Reunião de Antropologia do Mercosul, realizada em Porto Alegre em 2019. Agradeço os comentários de Fabiola Rohden e Claudia Fonseca, na ocasião. Além disso, agradeço a leitura e a contribuição preciosa de meus colegas Gleicy Schommer, Adalton Marques, Delcides Marques, Eduardo Rocha e Janis de Gouvêa. Sem a parceria de sempre, este artigo não seria escrito.

2 Para compreender a diferença entre um estudo de um problema histórico e um estudo de período ou contexto, ver Michel Foucault (2006 a), em "A poeira e a nuvem".

3 Existem ótimas pesquisas historiográficas que fizeram esse trabalho, dentre elas, destaco Abreu (2011) e Santos Filho (1991). 


\section{Sobre a economia política dos corpos}

Na primeira metade do século XVIII, a medicina portuguesa ainda não estabelecia relações diretas com a economia política e com a governamentalidade. Tratava-se, em geral, de uma apropriação dos tratados dietéticos da Antiguidade e do Medievo, e em especial da obra de Galeno e de seus reformadores. O galenismo escolástico orientava, majoritariamente - ainda que não exclusivamente -, o funcionamento das práticas médicas portuguesas, de modo que o ensino médico na Universidade de Coimbra se dedicava quase que exclusivamente ao problema das "paixões da alma" (Crespo, 1990). Essa questão central construía uma relação entre a medicina hipocrática e galênica - que centralizava suas estratégias na dietética, subjugando boticários e cirurgiões - e os problemas da alma, além de permitir um vínculo importante entre as práticas médicas e a orientação cristã de mundo. Um exemplo importante dessa dimensão tomista da medicina praticada em Portugal era seu caráter refratário aos estudos anatômicos e farmacêuticos, produzidos em outras partes da Europa (Abreu, 2011).

Até então, os saberes médicos, apesar de se constituírem ao lado e separadamente das práticas teológicas, eram submetidos às suas finalidades: uma vida terrena ausente de pathos, longe dos pecados e em direção à salvação da alma, de modo que a assistência aos doentes assumia preponderantemente essa perspectiva cristã ${ }^{4}$. Desse modo, essa medicina peripatética e tomista se mantinha controlada como espaço de um agente da apatheia cristã, mesmo quando seu objeto principal era conservar a saúde ou a cura de doenças por si mesmas. Apesar de Galeno não se apresentar como uma unanimidade entre os médicos portugueses, que criticavam essas limitações desde o início do século XVIII, e a medicina não representar as mesmas finalidades que a religião, o tomismo era um importante paradigma, uma encruzilhada teórica sob a qual os médicos portugueses produziam suas reflexões ante a tutela da Igreja.

Nesse caso, é fundamental frisar que para aquelas concepções tomistas de mundo, Aristóteles estava para a filosofia como Galeno estava para a medicina. Isso porque se Aristóteles ganhou a alcunha de "o" filósofo, Galeno se tornou "o" médico - mas esses epítetos não foram agraciados sem importantes revisões do ponto de vista teológico. Aliás, é bastante conhecido que um dos aportes importantes das sistematizações que Galeno fez dos elementos das obras de Hipócrates dependeu da filosofia aristotélica.

É somente na segunda metade do século XVIII (período pombalino ${ }^{5}$ ), com a lenta entrada de algumas publicações estrangeiras de influência iluminista em Portugal e o desenvolvimento refletido por parte dos médicos portugueses sobre as luzes, já com os olhos voltados para a nova medicina europeia, que a coincidência dos interesses médicos e políticos se tornaria uma pauta de investidura relevante. A saúde dos povos se tornou fundamental quando se percebeu que a riqueza das nações dependia crucialmente da vida dos indivíduos produtivos e longevos reunidos em um povo, e que os modos de existência e de coexistência dos homens precisavam ser dirigidos para melhorar as potencialidades do Estado - mercantil, militar e populacional. Questão mercantilista e, depois de economia política, que
4 Nos documentos das Constituições Sinodais de 1737, como observa Crespo (1990), fica bastante clara a relação de disputa entre Padres e Médicos na cura dos enfermos, pois ambos eram chamados em momentos de enfermidade. Alma e corpo, remédios morais e corporais em disputa. Aos médicos, era sempre lembrada a obrigação da realização do exame da confissão, conferido pelo sacramento da penitência, "para que a cura não fosse limitada pelos pecados”.

5 As reformas pombalinas são de fundamental importância para compreender essa relação de Portugal com o lluminismo. Por uma questão decorrente da economia do texto que aqui se apresenta, não será possível apresentá-las. Além disso, existe uma vasta produção sobre o assunto; para mencionar apenas um importante texto, Maxwell (1996). 
também se tornaria uma questão médica. Afinal, a medicina se apresentava como um importante aliado das forças vivas e produtivas dos Estados, podendo cumprir um papel fundamental na otimização dos elementos políticos implicados.

Podemos observar a emergência desse problema econômico e político da Medicina no mundo luso-brasileiro, entre vários tratados que abordam o assunto, nos textos médicos de Sanches (1757), Tissot ([1761] 1786) e Franco (1790). Esses três textos põem em relevo a maneira como se desenvolveu uma "politização" da medicina como arte de governar a saúde dos homens, além da associação de seus interesses com os do Estado. Evidentemente, esses não são os únicos e nem os primeiros a estabelecerem essas relações. A escolha dessas três obras permite alcançar mais claramente a questão desta primeira parte do artigo. Elas foram selecionadas para acompanhar, no âmbito médico luso-brasileiro, um movimento muito maior que elas representam ${ }^{6}$.

Os textos citados focalizam na saúde e no prolongamento da vida do homem, não mais pensado individualmente, mas como povo, ligando a medicina diretamente aos interesses dos Estados. O tema central de ancoragem é a "reta razão" do homem saudável, a dietética em todos os seus aspectos definidos por Galeno em Sanitae Tuenda, isto é, o cuidado com as "seis coisas não naturais" que influenciam a constituição da saúde: o ar e o meio, o exercício e o repouso, alimentação e as bebidas, o sono e a vigília, a evacuação e a repleção e, por fim, as paixões da alma. A dietética significava tudo o que dizia respeito aos hábitos corporais e mentais de um indivíduo na relação com o ambiente que o circunda. No entanto, a novidade desses tratados de higiene não está na orientação dietética para que os homens pudessem praticar a medicina de si mesmos, que é muito antiga e com inúmeras referências em Portugal, mas no vínculo entre essas práticas e a economia política por meio da preocupação com a saúde do povo.

Essa disposição política da medicina é bastante acirrada no Tratado da Conservação da Saúde dos Povos (1757), de Antônio Nunes Ribeiro Sanches ${ }^{7}$, que é um texto de pretensão universal e com maior clareza em relação ao lugar que a medicina gostaria de ocupar, na segunda metade dos oitocentos. $\mathrm{O}$ próprio autor $\mathrm{o}$ define como um tratado de "Medicina Política", contrastando-o com os tratados de medicina popular dirigidos a doentes ou à conservação da saúde individual. O objetivo do livro é claro: "nele pretendo mostrar a necessidade que tem cada Estado de leis, e de regramentos para preservar-se de muitas doenças e conservar a saúde de seus súditos" (Sanches, 1757, p. 2). O tratado disserta sobre os cuidados necessários ao desenvolvimento da vida na cidade, no campo, nos navios e em todas as instituições públicas, no sentido de melhorar o meio em que a vida se desenvolve. Por outro lado, disserta sobre a alimentação, a qualidade do sono e os exercícios físicos praticados por súditos e soldados. Essas práticas de si eram determinantes do problema, já que nenhuma lei poderia efetivamente combater os vícios nocivos à saúde, a não ser uma reforma moral da população.
6 A escolha da obra do médico suíço Samuel August David Tissot se dá pelo fato de ela ter sido um best-seller médico do século XVIII e porque teve grande circulação em Portugal, sendo uma das mais citadas pelos médicos portugueses e brasileiros. Para saber mais, ver Santos Filho (1991).

7 Iniciou seus estudos na Universidade de Coimbra, mas se transferiu para a Universidade de Salamanca, onde se tornou doutor em medicina em 1724. Foi aluno de Boerhaave na Holanda e membro de várias academias de ciências, incluindo a Academia de Ciências de Paris, em 1739. Enciclopedista a pedido de Diderot, autor que reconhecidamente teve boa influência nas reformas pombalinas e, nomeadamente, em relação às reformas dos estudos médicos, na Universidade de Coimbra. 
suas forças, poder, grandeza e majestade [...], Mas como poderá aumentar-se sem leis, regramento da Conservação da Saúde dos Povos, e curar as enfermidades a que estão expostos? (Sanches, 1757, p. 3).

Sanches pretendia, pois, por meio da gestão das "seis coisas não naturais", vincular diretamente a medicina com a administração pública. Enfim, colocar aquilo que até então operava numa dimensão exterior às preocupações do Estado, no conjunto de suas vísceras. Em suma, governamentalizá-lo através da arte da medicina, com o fim de colaborar com suas riquezas. Sanches advogava também que a medicina deveria se estabelecer em Portugal e seus vastos domínios - o Brasil é citado de maneira importante - como uma atividade civil, modernizada pelo desenvolvimento da ciência europeia e regida e controlada pelo Estado por meio de um Tribunal ou Ministério de Medicina. Assim, incentivava formas de proibição do curandeirismo, inclusive algumas práticas religiosas, "porque seus erros arruinavam a Fazenda" e eram demasiado perniciosos ao Estado.

Essa relação com a economia política também aparece como objetivo primeiro do Aviso ao povo acerca de sua saúde, do médico suíço Samuel Auguste Tissot - livro de 1761, com muitas edições e publicado em vários países da Europa. O texto foi traduzido em 1786 por Manoel Joaquim Henrique de Paiva', em Portugal. Paiva, por sua vez, justifica sua tradução por dois motivos: o primeiro, devido à importância do livro, dada a sua exatidão frente aos ensinamentos de Hipócrates e Galeno; o segundo, porque se tratava do texto médico mais lido do século XVIII (dadas as inúmeras traduções na Europa) e que finalmente Portugal teria acesso.

Segundo o autor, o livro é destinado àqueles que não poderiam consultar um médico, isto é, àqueles que moravam nas aldeias europeias, longe das cidades e onde, pela ausência de médicos, somente o poder eclesiástico fazia os "cuidados de saúde", às vezes de maneira desastrada e sem conhecimento de causa. Seu objetivo é combater a "despovoação" que afeta a riqueza dos reinos, combatendo suas causas.

A diminuição do número de habitantes deste país, é uma verdade de fato, que espanta todo mundo, e que as listas demonstram. Muitas são as causas dessa despovoação, e eu me tivera feliz se pudesse contribuir para remediar uma das principais, que é o mau método de tratar os enfermos nos campos (Tissot, 1786, p. 1).

A causa do despovoamento, segundo Tissot, é o "desregramento" das dietas, a maneira como se come, como se dorme, como se mora, como se exercita, mas também a limpeza do ambiente, do ar etc. Assim, os descasos com as "seis coisas não naturais" da dietética, descritas por Galeno, implicavam, no seu ponto de vista, em erros que custavam milhões de homens na Europa. Mas o livro combate, além disso, as técnicas errôneas utilizadas por padres para curar as doenças nas aldeias, sem conhecimento médico, que acabavam por tornar mais agudas as enfermidades e custando muito às nações. Esse é um trabalho simples, como afirma o próprio autor, de vulgarização da medicina para que padres e outras pessoas iniciadas nas letras, pudessem exercer esse escasso e fundamental ofício de conservação da saúde. "Este trabalho é igual ao que teria escrito um Pároco, que
8 Esses temas também são tratados, em particular em outra publicação do autor: Apontamentos para estabelecer-se um Tribunal e Colégio de Medicina, de 1763. Esse texto remete ao conjunto de obras produzidas sob o pagamento da Coroa de Portugal, no contexto das reformas pombalinas. 9 Médico português formado na Universidade de Coimbra, em 1781. Em 1795, foi nomeado médico da Casa Real Portuguesa. Foi perseguido a partir de 1808, por simpatia a Napoleão e aos ideais liberais, o que o levou ao exílio em 1809. Em 1822, naturalizou-se brasileiro, e seu último cargo foi como professor, na Academia Médico-Cirúrgica da Bahia. 
escreve um catecismo para os meninos" (Tissot, 1786, p. 16). O fato é que a fraqueza decorrente da má dietética impossibilita a relação produção/reprodução da vida, diminuindo as capacidades do bom funcionamento do Estado e suas forças.

Na mesma direção, aponta o tratado de puericultura escrito pelo médico brasileiro Francisco Mello Franco ${ }^{10}$, mas dedicado às famílias citadinas. Segundo o autor, o povo português multiplicava-se bem, mas deixava sua prole morrer no berço e nos primeiros anos, o que diminuía o povoamento do Estado e, portanto, suas forças.

Essa origem da despovoação, e da degeneração da espécie humana merece toda a atenção do Ministério; porque sem vassalos, e vassalos robustos, o Estado necessariamente virá a ficar paralítico sem forças, sem energia, e tendendo cada dia para sua inteira ruína (Franco, 1790, p. 6).

Como resposta a esse dado alarmante e nocivo à sociedade lusitana, seu tratado serviu para uma reorientação no cuidado dos filhos por parte dos pais, no sentido de atenuar os problemas governamentais, para que os portugueses do futuro não somente sobrevivessem, aumentando o número de súditos do Estado, mas que esses fossem robustos, capazes de intelecto e trabalho pesado:

Portanto, aos pais que aspirarem o prazer de procriar filhos vigorosos, e felizes, devem regular-se segundo os ditames da reta razão; convém a saber, devem nutrir-se de alimentos sãos, e ordinários; respirar um ar aberto, e corrente, e exercitar-se sem fadiga (Franco, 1790, p. 2-3).

Os três tratados que selecionei, um dirigido aos governantes, outro dirigido ao povo que não tinha acesso à arte da medicina e o último, dirigido aos pais no cuidado com seus filhos, estavam coadunados em criar uma conexão entre a saúde das pessoas e da população com a saúde econômica e política do Estado. A qualidade de vida dos povos fora repercutida nas forças que impulsionavam os Estados do qual faziam parte, e essa relação deveria ser tratada pela medicina política, sob um duplo aspecto: por criações de leis que regulamentavam o ambiente, o meio em que a vida se desenvolve e por uma reforma moral da população, através da popularização das práticas dietéticas.

A medicina, assim, não deveria ser mais uma atividade estranha à política e ao Estado; ela se apresentaria como um de seus centros de gravidade. Enfim, essa medicina é coletiva em suas estratégias e tem o bem-estar do Estado como finalidade, mesmo quando trata os sujeitos individualmente por meio de prescrições dietéticas. Por isso, ela não deveria funcionar mais para uma determinada elite de pessoas, mas dirigida a todo o conjunto da população - daí sua atenção cada vez maior com a classe trabalhadora e pobre. Em resumo, uma medicina de Estado, coletiva, atuante sobre o "meio" e implicada com a finitude do homem e sua força de trabalho ${ }^{11}$.

De minha parte, o que quero ressaltar é que esse acontecimento no século
10 Médico brasileiro nascido em Paracatu, Minas Gerais, e radicado em Portugal. Por suas ideias liberais, viu-se condenado e preso pelo Tribunal da Inquisição. Formou-se em medicina pela Universidade de Coimbra, em 1786. Foi médico da Casa Real e se tornou correspondente da mesma, em Lisboa, na Oficina da Academia Real das Ciências, em 1790. Mudou-se para o Brasil em 1817, aportando no Rio de Janeiro, acompanhando a princesa-consorte Leopoldina.

11 Esses elementos da transformação da medicina foram bem descritos por Foucault (2011), no contexto da França, da Inglaterra e da Alemanha. Penso que é fundamental e uma importante contribuição, recolocar alguns dos elementos dessa descrição da medicina social, por meio das teses do próprio Michel Foucault a respeito da governamentalidade liberal e sua disposição na subjetividade. Isso significa problematizar a medicina social 
XVIII representou muito mais que uma "medicina social” na sua dimensão coletiva e normativa (Foucault, 2011; Rosen, 1994), porque o que ela aspirou foi uma forma de governamentalidade da população no quadro do Estado, que levava em conta uma prosaica liberdade dos sujeitos. Isso é, a relação que cada um estabelece consigo mesmo no que diz respeito à sua saúde. $\mathrm{O}$ trabalho dos médicos, então, era construir um elo dessas práticas de si mesmo, que já estavam relativamente dadas historicamente, através das práticas dietéticas hipocráticas e galênicas, para recolocá-las à disposição do Estado através de uma nova tecnologia de governo (a economia política: primeiro mercantil e depois liberal), que se apresentava segundo novas demandas e aspirações.

A essa finitude valorizada da vida vivente, impulsionada pelos interesses da economia política e tensionada pelo saber médico, o vitalismo e o neo-hipocratismo foram convidados a responder, sob o nome de Higiene. A Higiene se transformou, assim, em um dos importantes operadores da transformação da noção de "vida" e, portanto, da aporia, que até nossos dias correlaciona o simples fato de viver com o viver bem.

\section{Da necessidade de prolongar a vida}

No mundo luso-brasileiro do início do século XVIII, é possível perceber que a noção de "vida" era orientada, até então, predominantemente sob a perspectiva teológica tomista, baseada na leitura cristã de Aristóteles. No volume VIII do dicionário de Bluteau (1721), por exemplo, o verbete "vida" separava e definia a "vida substancial", "que é Deus, no sentido de fonte de toda a vida comunicada" e "vida animada", entendida como "o espaço tempo entre a vida e a morte". Ainda, segundo o dicionário, a vida humana consistia na união entre corpo e alma, isto é, numa junção destas instâncias: "os alimentos que sustentam a vida animada" e o "santíssimo Sacramento que leva a bem-aventurança”. Vida secular e vida religiosa.

Evidentemente, essa é uma definição teológica de vida, na qual a vida temporal é somente um instrumento para se alcançar a eternidade - "o homem nasce para morrer e morre para sempre viver”. Aqui a alma é a substância da vida e aquilo que anima o corpo e, por isso, ultrapassa o acontecimento da morte na direção da vida eterna. Nesse sentido, o verbete anunciava aos homens "a vida que vale a pena ser vivida", a vida eterna, já que aqueles que valorizam a vida temporal, no sentido de sua dilatação, "fazem com que a vida fuja”. Prolongar a vida vivente jamais poderia representar um objetivo que não fosse mundano.

É somente na virada para o século XIX que os médicos dos domínios portugueses criariam uma fissura na relação entre "vida animada" e "vida substancial", que sustentava a concepção cristã e a medicina a ela subordinada. Ela estava amparada no desenvolvimento europeu da medicina (notadamente, a anatomia e a fisiologia experimental), que finalmente passaram a fazer parte do ensino médico em Portugal, a partir das reformas dos estatutos da Universidade de Coimbra em 1772, amparados, em boa parte, pelas contribuições de Antônio Nunes Ribeiro Sanches. no quadro geral da biopolítica e das técnicas de si, que foram elaboradas somente anos depois pelo autor em seus cursos no Collège de France e nos volumes da História da Sexualidade. Além disso, tomar esse problema pelo elemento da dietética significa abrir novas direções para o debate acerca da política da vida. 
Uma nova disposição da vida será colocada em disputa pela medicina por meio do vitalismo, para assim contribuir com o acontecimento que a tornará autofinalizada por meio da noção-chave de “organização”. Segundo essa nova lógica, cada um dos seres contém em si mesmos a razão de sua existência, seu princípio vital. O vitalismo é a expressão da identidade da vida com ela mesma, uma filosofia da vida que instaura na imanência do vivido todas as explicações do ser.

Afinal, como demonstraram por caminhos distintos, François Jacob (1983) e Georges Canguilhem (2011), se o mecanicismo físico da filosofia clássica contribuiu como um princípio de observação das estruturas visíveis dos corpos vivos, opondo-se aos animismos mágico-religiosos, o vitalismo fisiológico-químico permitiu nomear de vida a "organização oculta" atrás dessas estruturas, encerrando-a em sua própria finitude e se tornando a razão única da existência dos seres vivos. $\mathrm{O}$ vitalismo, nas suas mais variadas correntes, foi o mais importante componente para o desenvolvimento inicial da história moderna da noção de vida e encontrará seu eco final no nascimento da biologia. O corpo não será mais um componente passivo que a alma - enquanto substância da vida - movimenta e atualiza. $\mathrm{Na}$ crítica ao modelo aristotélico, a vida ganha uma nova ontologia.

Mais uma vez, gostaria de tomar a obra de Francisco de Mello Franco como expressão dessa discussão no domínio luso-brasileiro. Em 1814, essas preocupações estavam bem organizadas na obra Elementos de Higiene ou ditames teóricos e práticos para conservar a saúde e prolongar a vida, que apresenta uma primeira parte "antifilosófica”, destinada a uma discussão sobre a problemática da vida. Para realizar tal empreitada, Francisco de Mello Franco se orientou nas contribuições do mecanicismo filosófico da Idade Clássica, mas principalmente nas críticas a essa corrente, provenientes do vitalismo fisiológico-químico contemporâneo a ele. Essa discussão se realiza contra Aristóteles, em De Anima e, portanto, contra o tomismo, que, em geral, apoiou-se nessa obra para a própria definição religiosa de vida.

Em Elementos de Higiene, a vida é tratada como lei que faz com que os "corpos organizados" se nutram, movam-se e que crucialmente, "resistam à morte". A noção de "corpos organizados" define o que permite a vida e o que é determinado por ela - no sentido de que a vida é uma força que se diferencia das leis que regem os minerais (que são denominados como corpos brutos), apesar de participar, tanto fisicamente quanto quimicamente, dos mesmos princípios. Assim, graças à "organização" das leis que regem os corpos, eles podem ser diferenciados em "vivos" e "brutos", a saber, reino vegetal/animal e os minerais. Afinal, a vida é tomada a partir de sua capacidade de morte e definida como o conjunto das funções que resistem a ela ${ }^{12}$.

É da observação de todos, que só corpos organizados nascem, crescem, nutrem-se, propagam-se e morrem. A vida é o resultado da lei, ou força desconhecida, que solicita todas essas operações. A organização pertence aos dois Reinos, animal e vegetal: e por isso em ambos os seus respectivos indivíduos nascem e morrem. E como a morte é diametralmente oposta ao
12 Essas reflexões estão muito próximas da argumentação de Georges Cuvier, em Leçons de d'anatomie compararée ([1800] 1835) e de Marie François Xavier Bichat, no seu Recherches physiologique sur la vie et la mort ([1800] 1822). Sabe-se que em suas respectivas áreas, história natural e fisiologia experimental, Cuvier e Bichat são expoentes do movimento vitalista na França, que encontrariam desdobramentos em toda a Europa. 
que se chama de vida, não podemos negar a esta [...] a prerrogativa vital; porque sem esta não pode haver morte (Franco, 1814, p. 1).

Ora, aquilo que Aristóteles denominava de "alma", a saber, alma vegetativa, alma sensitiva e alma intelectiva, se transformará, sob a perspectiva vitalista de Franco, em um domínio das funções vitais orgânicas. Para Aristóteles os corpos eram animados pela alma como potência, sendo a alma em si mesma a disposição da vida; na modernidade iluminista, encampada por Franco, a alma é resultado da dinâmica das funções de um corpo organizado, sendo a organização o princípio da vida. Todas as vezes que Aristóteles utilizava a palavra "alma", Franco a substituiu pela palavra "vida", argumentando sobre a vida vegetativa, a vida sensitiva e a vida intelectiva. E não se trata de um nominalismo. A vida é agora organização como função imanente, portadora de razão em si mesma e observável no funcionamento do corpo. Enfim, a alma, outrora potência fundamental da vida, torna-se somente um termo decorrente dela; a vida nada mais é do que organização, ou a economia das funções físico-químicas que resistem à morte.

Elementos de Higiene - seguindo a divisão argumentativa de Aristóteles, em De anima - separa em dois os princípios da vida: latente e ativa. O primeiro princípio da vida é vinculado aos ovos, sementes e aos corpos dos animais em sono profundo e entorpecidos pelo frio - enfim, ao estado em que não há movimento sensível e que a vida se encontra em uma forma pura e primeira, funcionando sob si própria. O segundo princípio inicia-se como o processo de resistência à morte, comum a todos os seres vivos, colocando em movimento os sólidos e os fluidos que compõem os corpos organizados, no conjunto da assimilação e da excreção. Assim, o corpo humano - como todos os seres vivos -, enquanto um composto de órgãos, funciona como um "laboratório vital" que é repulsivo ao que não é vivificante. $\mathrm{O}$ epigástrio (diafragma, estômago e intestinos) formam, junto com o cérebro e o coração, o "triunvirato do corpo humano" (Franco, 1814, p.1).

Esses dois princípios de vida (latente e ativa) formam, em conjunto, uma primeira forma geral de vida, a que o autor dá o nome de vegetativa, a qual é atribuída a todos os seres vivos: animais, vegetais, insetos, humanos etc., e radicalmente oposta aos minerais. A vida vegetativa pode ser observada em dois sentidos: nutrição e reprodução, de modo que a primeira pertence ao indivíduo e a segunda à espécie. "Logo a vida vegetativa, que principia e só acaba quando a organização se destrói, é a vida radical; à proporção que os órgãos que a formam se deterioram, falta a saúde" (Franco, 1814, p. 4). Ora, a forma de vida de qualquer vivente é definida por sua capacidade de se nutrir, de crescer e de se reproduzir, definindo-se em resistência à morte.

Há ainda uma segunda forma de vida, que os animais, diferente dos vegetais, também são portadores: a vida sensitiva, forma intermediária de vida, que é representada pelos instintos e por um conjunto de sensações disponíveis que operam o movimento e, até mesmo, certo grau de razão que não é perfectível como no homem. Ela significa a manifestação dos instintos e das sensações dos animais frente aos vegetais, como a dor, a fome, as emoções, assim como sua capacidade 
imperfeita de comunicação e organização. Essas duas primeiras formas (vida vegetativa e vida sensitiva) são opostas à vida intelectual. Esta última vida é somente possuída pelo homem, em detrimento aquelas dos animais e dos vegetais, respectivamente. Ela é representada pela capacidade intelectiva, que permite formular conceitos abstratos e combiná-los extensamente com formas morais.

A partir da "vitalização" do modelo Aristotélico, Francisco de Mello Franco contribui para promover uma transformação importante no sistema. Uma transformação na ordem de importância hierárquica das vidas, por meio de uma nova sequência lógica: a vida intelectual e a sensitiva tornam-se somente acessórias à vida vegetativa. Sua argumentação é interessante: "há tantos homens que vivem apesar de terem perdido o uso da razão, como existem doentes que perdem um ou mais membros e não perecem" (Franco, 1814, p. 5). Assim, apesar de tratar de todas as formas de vida no homem, a medicina deveria considerar, em primeiro lugar, sua forma primeira: a vida vegetativa, com seus princípios nutritivos e reprodutivos.

O médico luso-brasileiro, a fim de justificar sua entrada nesse campo de reflexão "filosófica" a respeito da "vida", critica diretamente as definições provenientes da "filosofia", como se essas fossem do passado. "Deliram os grandes filósofos", porque dizem que a vida nasce do ar, do fogo, ou até mesmo que a "alma humana e o princípio vital eram os mesmos e constituiriam a alma universal, de onde todos os entes organizados tiram a vida, sendo esta uma mera emanação daquela". A alma é eterna - afirma ele: "esse é um dogma de fé que professamos" (Franco, 1814, p. 6-7) -, mas a vida não. Um organismo somente é vivo se capaz de morte, e se sua morte encadeia - por processos ulteriores da economia natural - a manutenção da vida em geral.

A "alma vegetativa ou nutritiva", conforme Aristóteles em seu texto sobre a alma, apesar de primeira e universal aos seres vivos era somente uma base, numa escalada que passaria pela "alma sensitiva" até chegar na "alma intelectiva", como a forma perfectível de vida. A vida vivente era somente o princípio lógico e um bem apenas na medida em que representava a base sobre a qual o viver bem, decorrente da interrogação ética, se tornava possível. Assim, enquanto para Aristóteles as definições de alma eram uma argumentação em direção à superioridade do homem frente aos outros seres vivos, a noção de organização, enquanto princípio vital, transformou-se na chave que permitiu diluir o homem no quadro da "vida" em geral. "O isolamento da vida nutritiva (a qual os comentadores antigos já chamavam de vegetativa) constitui um evento de toda maneira fundamental para a ciência ocidental" (Agamben, 2017, p. 29).

Essa mudança de paradigma representada aqui, para o mundo luso-brasileiro através da obra de Mello Franco, não é trivial. Sabe-se da duração histórica da argumentação de Aristóteles e como a cosmologia cristã medieval lhe deu continuidade, em seus próprios termos. $\mathrm{O}$ problema da vida, tal como já se apresentava em alguns textos iluministas da Enciclopédia, pôde ser compreendido como uma questão de economia animal; e não obstante, na divisão dos saberes e em oposição às ciências do homem, a medicina ficava alocada na seção da zoologia. Assim, o vitalismo da virada do século XVIII para o XIX reajustou o jogo da vida, no sentido 
daquilo que Aristóteles justamente combatia em sua ética: agora a vida qualificada do homem pode estar destinada à manutenção e ao desenvolvimento da vida vivente como uma de suas finalidades.

É preciso ressaltar, entrementes, que nesse caso o debate a respeito da verdade da "vida" é produzido em meio ao desenvolvimento de um manual de Higiene, que, como ressalta o próprio Francisco de Mello Franco, é o novo domínio da dietética.

\section{Higiene, o novo território da dietética}

Essa crítica ao modelo aristotélico, aclimatado através das correntes tomistas de visão de mundo, atingia diretamente a centralidade de Galeno na medicina luso-brasileira, dando vazão ao movimento neo-hipocrático, representado por essa leitura vitalista da vida. Segundo essa perspectiva, "Galeno era incompatível com a modernidade. Hipócrates não. A união entre Hipócrates e Galeno, que resistira a milênio e meio de história, tinha finalmente chegado ao fim (Dias, 2010, p. 87). As "seis coisas não naturais" da dietética galênica, de Sanitae Tuenda, tornar-se-iam "Circumfusa, applicata, ingesta, gesta, excreta e percepta" e, assim, transformadas em "seis coisas naturais"13.

Desde Galeno, têm os médicos chamado as coisas mais indispensáveis, e naturais à existência do homem, de "coisas não naturais"; convém, a saber, o ar, os alimentos; o movimento e o repouso; o sono e a vigília; as paixões; e enfim as secreções e as excreções. Parece incrivel que Galeno, um homem de tanto saber e discernimento, tenha dado a coisas tão naturais o nome de "não naturais": e ainda mais incrivel é que a dois mil anos tenha sido conservado em todas as Escolas de Medicina (Franco, 1814, p. 11).

Do ponto de vista teórico, Higiene é o nome dado a essa reinvenção das práticas dietéticas antigas e medievais pelo vitalismo em sua entrada na ordem biopolítica (Pugliese, 2015). Portanto, ela é vitalista em seu saber sobre a vida e neo-hipocrática no que diz respeito às suas tecnologias de governo. Neo-hipocrática porque permitia - na contramão das leituras tomistas de Galeno - justamente uma natura medicatrix. Elementos de Higiene, de Francisco de Mello Franco, mais uma vez será tomado como exemplo de um movimento maior, pois como se pode observar, a divisão de sua obra segue exatamente essa importante sequência neo hipocrática, mencionada acima ${ }^{14}$. O livro é dividido em uma introdução e mais seis seções, cada uma dedicada a uma das "coisas naturais".

A introdução compreende a reflexão sobre a vida - discutida na seção anterior deste artigo. Além disso, é composta por uma reflexão sobre a decadência dos hábitos do homem em sociedade e os decorrentes perigos econômicos e militares para o Estado Português, assim como a idade, o sexo, os hábitos e os temperamentos influem sobre a saúde, ou seja, os elementos condicionantes da dietética. A segunda seção é destinada a discutir a Circumfusa: as causas que cercam o homem, a saber, o magnetismo, o clima, os solos, as água, as localidades e as habitações,
13 Essa série de longa vida na história da medicina foi reestabelecida sob a ótica neo-hipocrática somente em 1792, pelo médico francês Jean-Nöel Hallé - médico de Napoleão Bonaparte e presidente da Academia de Ciências na França, em 1813. Sabe-se que Hallé foi um dos pioneiros do movimento higienista na França. Foi ele que reeditou as obras completas de Samuel August Tissot, entre 1809 e 1813 , no seu país.

14 A extensão desse movimento neo-hipocrático (já tomado pelo vitalismo) pode ser observada na Europa, com fartos exemplos até o final do século XIX. No domínio luso-brasileiro, os médicos do Império representam essa perspectiva, fazendo das seis coisas naturais seu objeto privilegiado. O fato é que essas reflexões podem ser encontradas majoritariamente até pelo menos a década de 1870 , inclusive, orientando a maior parte da produção das 
e a applicata: tudo o que se aplica à superfície do corpo, como banhos, vestimentas, cosméticos, miasmas, venenos, vírus etc. A terceira seção, e a maior parte do texto, é relativa à ingesta: substâncias que no estado normal do organismo são ingeridas na economia animal, em suma, a alimentação e a inspiração; exemplos são alimentos, bebidas, temperos, condimentos; fumos, fumaça, etc. A quarta trata da gesta: a ginástica e os exercícios físicos, as funções genitais, o repouso, o sono e a vigília. A quinta trata da excreta: tudo aquilo que o corpo joga para fora de seu domínio quando são inúteis ou quando já utilizadas - transpiração, dejetos, urina, ejaculações seminais, muco nasal estão envolvidos, mas principalmente, o urinar e o defecar são seus objetos. E, por fim, a sétima desenvolve a percepta: funções cerebrais, faculdades intelectuais e afetivas e os sentidos externos, enfim, a influência do físico sobre a moral e a influência da moral sobre o físico, numa releitura da teoria dos humores e dos temperamentos ${ }^{15}$.

Essas seções representam os "ditames teóricos e práticos para conservar a saúde e prolongar a vida”, subtítulo da obra. São compostas de prescrições médicas sobre como governar o meio e os indivíduos reunidos em uma população. Desse modo, a higiene deveria ser aplicada ao ambiente através de leis e regulamentos, além de como uma medicina de si mesmo: o gênero de vida dos homens tomado como um problema e orientado pelo saber médico, para que possa ser colocado politicamente à disposição do Estado. Essa tecnologia médica, portanto, se dividia em duas partes indissociáveis: a "parte pública", que compreendia o melhoramento do clima, dos lugares, das habitações, dos costumes e das leis, ou seja, tudo aquilo que concerne à higiene enquanto matéria de governo e política; e a "parte privada", que tinha por objetivo o regime do homem, considerado individualmente e em sua singularidade, na sua intimidade, naquilo que ele faz de si mesmo e com seus próximos.

A ideia do médico era introduzir novos hábitos no mundo luso-brasileiro, "onde residem valetudinários e frouxos", doentes e incapazes de contribuir com a sociedade. Esse seria o estado calamitoso do Império português e, por conseguinte, de todas as suas colônias. Nesse caso, era importante insistir com os governantes e o soberano acerca da importância dessas práticas.

Gente fraca que foi sempre educada na efeminação, de pouca utilidade servirá ao Estado; porque é insuficiente para as armas e para o trabalho, e pouco própria para as letras, mas não assim para os vícios, companheiros da inércia (Franco, 1814, p. 241).

No entanto, a respeito dos governantes, o médico deixa claro que "leis não bastarão" para fazer com que essas importantes práticas de saúde se disseminem. Segundo ele, somente meios indiretos e "discretamente conduzidos" serão efetivos para incitar os sujeitos à prática dietética, que possibilitará a existência de um "verdadeiro cidadão português". Esse, aliás, é o objetivo último do Elementos de Higiene, e por isso ele se dirige a seus concidadãos, porque se essa tarefa fosse cumprida, eles fariam, enquanto patriotas, "respeitar nas quatro partes do Globo
Faculdades de Medicina, que abordavam essa série, ora separadamente, ora agrupados para reflexão conjunta (Ferreira, 1996; Gondra, 2004; Pugliese, 2015).

15 Por conta da extensão deste texto, não será possível uma análise detalhada da série neo-hipocrática. Ela pode ser encontrada em Pugliese, 2015. 
a valorosa Nação Portuguesa” (Franco, 1814, p. 347).

Essas mesmas preocupações higiênicas estão expressas em Reflexões sobre alguns meios propostos por mais conducentes para melhorar o clima da cidade do Rio de Janeiro (1808), do físico-mor Manoel Vieira da Silva ${ }^{16}$. Nesse texto, encomendado pela Família Real portuguesa recém-chegada ao Brasil, e que é considerado o primeiro trabalho de saúde pública escrito no país, o autor pretende aproximar o "trono português com os vassalos brasileiros, no sentido de promover sua felicidade”, já que o Brasil “entraria na história das nações policiadas”. Diz o texto:

A causa da saúde pública em todos os tempos tem merecido as primeiras atenções dos grandes Legisladores; quando o número dos indivíduos sociais tem diminuído, impossibilita-se a execução da lei, muda o seu objeto e, em consequência, a sua natureza, que deve ser relativa ao estado da população; e se o descuido chega a permitir a reunião de todas as causas capazes de atacar rapidamente o princípio vital, a sociedade em muito pouco tempo é quase toda vítima do seu fatal estrago; de que oxalá não existissem tantos exemplos (Silva, 1808, p. 5).

Esse texto, escrito pelo físico-mor, abriu espaço para um conjunto de publicações sobre as condições de saúde no Brasil. É sobre essa tutela que o texto intitulado Prolegômenos, ditados pela obediência, que servirão às observações, que for dando das moléstias cirúrgicas do país, em cada trimestre (1820), de Domingos Ribeiro dos Guimarães Peixoto ${ }^{17}$, se apresenta. A despeito de seu título, trata-se de um trabalho sobre Higiene, com uma tônica já conhecida:

Um sem-número de causas morbíficas e muito diversas nos podem afetar com maior ou menor prontidão, imprimindo em nossa organização um modo de existir muito diferente e análogo a sua ação: aqui se achando dispersa no seio da atmosfera, e em torno de nós - circunfusa; ali postas em contato com o nosso corpo - applicata, de uma parte introduzida nos nossos órgãos - ingesta; de outra existindo dentro de nós mesmos e dependem do desarranjo das evacuações, dos movimentos e das paixões - excreta, gesta et percepta. É fora de dúvida que o ar atmosférico pelas qualidades físicas, as diversas estações do ano, a situação dos países em que se vive, os alimentos de que se faz uso, as paixões, as profissões, os hábitos etc, imprimem em nós uma tão variável, quanto diferente são as impressões que eles nos fazem (Peixoto, 1820, p. 88-89).

Desse modo, o autor dos Prolegômenos defende a Higiene pública e privada como forma de prevenir diversos males e prolongar a vida dos indivíduos, colocando-a em primeira importância em relação à terapêutica, pois a "saúde é o mais precioso bem que podemos possuir, e para cuja conservação é mister haver boa conduta na aplicação dos agentes necessários à nossa existência” (Peixoto, 1820, p. 94). A saúde, esse bem maior, é quem dá felicidade à nação, "conservando a
16 Médico, formado na Universidade de Coimbra, fidalgo da Casa Real e do conselho de D. João. Foi nomeado físico-mor com a chegada da Família Real, em 1808, cargo médico mais importante da administração portuguesa. Em 1818, recebeu o título de primeiro barão de Alvaiázere. Em 1821, regressou a Portugal junto com D. João VI.

17 Formou-se em cirurgia pela Escola Anatômica, Cirúrgica e Médica do Rio de Janeiro, em 1812. Foi nomeado cirurgião da Casa Real em 1817, cirurgião da Real Câmara em 1820 e lente de fisiologia da Academia Médico-Cirúrgica do Rio de Janeiro em 1822. Realizou seu doutorado em Paris (1827-1831), assumindo em seu retorno a direção da Faculdade de Medicina do Rio de Janeiro (1832-1839). Em 1845 recebeu o título de Barão de Iguaraçu. 
preciosa vida aos soberanos, concorrendo a prosperidade aumento as ciências e das artes, do comércio e agricultura" (Peixoto, 1820, p. 94). Somente assim se mantém o vigor da população, fazendo com que a administração pública, mas também cada um em sua própria "liberdade", contribuísse espontaneamente com práticas higiênicas em prol de toda a sociedade. Afinal, desprovido da preciosa saúde, "o homem é um ente desgraçado, torna-se objeto de compaixão e horror até para com os outros homens” (Peixoto, 1820, p. 94).

\section{Reflexões finais}

Pode-se dizer que, dado o exposto anteriormente, a maior "contribuição" da Higiene à atualidade da biopolítica, antes mesmo de um poder normativo, sanitário e institucional consagrado no final do XIX (muito bem descrito pela historiografia sobre o tema no Brasil), seja a cristalização do axioma de que viver bem é viver com saúde. Não que a saúde tenha passado a ser valorizada somente nas imediações oitocentistas; sabemos que ela é um elemento seriamente considerado desde tempos inenarráveis da história do Ocidente. Contudo, a sistematização e a centralização da saúde como um possível telos da própria vida é, certamente, somente possível com a finitude do homem, decorrente de concepções vitalistas, enfim, quando a vida se estabelece no jogo limitado das suas funções.

A Higiene, assim, apresentou-se como uma arte de governar a saúde dos homens, através da relação entre seus hábitos e o ambiente em que vivem. Seu objetivo era refundar o gênero de vida do homem e as suas mazelas diante das circunstâncias estabelecidas pelo ambiente. Tudo se passa como se o interesse e a diligência dos governantes e de cada um dos indivíduos a respeito das condições de saúde dos regimes de vida pudessem, em linhas gerais, contribuir para o bem-estar de uma sociedade que, enquanto estoque vital, se tornaria mais produtiva e mais próspera, útil às aspirações dos Estados.

Não foi por coincidência, como forma de prescrição geral de como viver bem, que a Higiene se dedicou tanto, durante o século XIX, a combater os vícios, os desvios de conduta, como alguns dos inimigos principais da longevidade e da felicidade humana. Essa vida é a condição e o efeito da maneira como o homem pode adotar um modo de vida que prolonga a sua existência vivente e de seus descendentes, em determinadas condições ambientais. A vida qualificada a serviço da vida vivente encontra no fato de viver mais e com saúde uma modalidade de liberdade e de felicidade. Daí a estranha correspondência que viver bem significa viver com saúde, na mesma medida em que para viver com saúde é preciso bem viver. Estranha, porque ela não encontra lugar histórico no saber tradicional ocidental.

Nesse sentido, já estavam "fundados" os alicerces subjetivos de uma "ética-somática” (Rose, 2013), de uma vida dedicada e dirigida ao cuidado com a saúde (aquela que Platão e Aristóteles descreviam como o "infeliz modo de vida do doente") e que tem como ponto de ancoragem uma "liberdade", que é o cerne político da qual se alimentava a razão de Estado liberal, que se tornava dominante. Essa aporia da existência humana, gestada como um acontecimento histórico pela Higiene, responde à economia política como um princípio de rentabilidade estatal 
e uma estranha ética, que coloca a liberdade do sujeito em relação à forma que ele governa a si mesmo, em matéria de saúde, no centro das disputas biopolíticas. Essa experiência produzida na passagem do século XVIII para o século XIX, foi imediatamente convidada a se tornar dominante. Assim, a própria vida e a saúde puderam se tornar, pouco a pouco, direitos fundamentais.

De minha parte, o mais curioso não é que esses tratados de Higiene, muito comuns em todo o século XIX, apresentassem o cuidado individual com a saúde quase como uma atividade cívica fundamental, um ponto de conexão entre o interesse privado dos sujeitos em relação à sua saúde e a "razão de Estado". Surpreende-me, que nenhum médico tenha formulado esse fio que liga os sujeitos e a economia política por meio de uma mão invisível, mesmo quando já estavam dadas as bases da saúde como um capital humano.

Recebido: 07/08/2019

Aprovado: 14/10/2019 


\section{Referências}

ABREU, Jean Luiz Neves. Nos domínios do corpo: o saber médico luso-brasileiro no século XVIII. Rio de Janeiro: Editora Fiocruz, 2011.

AGAMBEN, Giorgio. O aberto: o homem e o animal. Rio de Janeiro: Civilização Brasileira, 2017.

ARENT, Hannah. A condição humana. Rio de Janeiro: Forense Universitária, 2010.

ARISTÓTELES. De anima (Sobre a alma). São Paulo: Editora 34, 2006.

BLUTEAU, Raphael. Vocabulário português e latino. Lisboa: Real Colégio das Artes da Companhia de Jesus. v. VIII. p. 1712-1728.

BICHAT, Xavier. Recherches physiologique sur la vie et la mort. Paris: Gabon, 1822.

CANGUILHEN, Georges. O conhecimento da vida. Rio de Janeiro: Forense Universitária, 2012.

CRESPO, Jorge. História do Corpo. Lisboa: Difel, 1990.

CUVIER, Georges. Leçons d'anatomie compararée. Tome I. Paris: Crochard et C. Libraires, 1935.

DIAS, Jose Pedro Sousa. Até que as Luzes os separem. Hipócrates e Galeno na literatura médico-farmacêutica portuguesa dos séculos XVII e XVIII. In: ANASTÁCIO, Vanda; CASTRO, Inês de Ornellas (Eds.). Revisitar os saberes: referências clássicas na Cultura Portuguesa do Renascimento à Época Moderna. Lisboa: Centro de Estudos Clássicos -FLUL; IELT; Universidade Nova de Lisboa, 2010.

FOUCAULT, Michel. A poeira e a nuvem. In: Ditos e Escritos, IV. Rio de Janeiro: Forense, 2006a.

FOUCAULT, Michel. História da sexualidade I: a vontade de saber. São Paulo: Edições Graal, 2006b.

FOUCAULT, Michel. Segurança, território, população. São Paulo: Martins Fontes, 2008a.

FOUCAULT, Michel. O nascimento da medicinal social. In: Ditos e escritos VII: arte, epistemologia, filosofia e história da medicina. Rio de Janeiro: Forense Universitária, 2011.

FERREIRA, Luiz Otávio. O nascimento de uma instituição científica: o periódico médico brasileiro da primeira metade do século XIX. Tese (Doutorado em História Social) Faculdade de Filosofia, Letras e Ciências Humanas, Universidade de São Paulo, São Paulo, 1996.

FRANCO, Francisco de Mello. Tratado de educação física dos meninos para uso da nação portuguesa. Lisboa: Academia Real de Ciências, 1790.

FRANCO, Francisco de Mello. Elementos de higiene ou ditames teóricos e práticos para conservar a saúde e prolongar a vida. Lisboa: Tipografia da Academia Real de Ciências, 1814.

GONDRA, José Gonçalves. Artes de civilizar: medicina, higiene e educação escolar na Corte Imperial. Rio de Janeiro: EDUERJ, 2004.

GALENO. A translation of Galen's Hygiene (De Sanitate Tuenda). Trad. de R. M. Green. Springfield: Charles C. Thomas, 1951.

CAIRUS, Henrique F.; JUNIOR, Wilson A. Ribeiro (Orgs.). Textos hipocráticos: o doente, o médico e a doença. Rio de Janeiro: Editora Fiocruz, 2005.

JACOB, François. A lógica da vida: uma história da hereditariedade. Rio de Janeiro: Edições Graal, 1983. 
MAXWELL, Kenneth. Marquês de Pombal: paradoxo do iluminismo. Trad. de Antônio de Pádua Danesi. Rio de Janeiro: Paz e Terra, 1996.

PEIXOTO, Domingos Ribeiro dos Guimarães. Prolegômenos, ditados pela obediência, que servirão às observações, que dando das moléstias cirúrgicas do país, em cada trimestre. In: SILVA, Manoel Vieira da Silva; PEIXOTO, Domingos Ribeiro dos Guimaraes. Saúde Pública no Rio de Dom João. Rio de Janeiro: Senac; Prefeitura do Rio de Janeiro, 2008. [Edição original: 1820].

PUGLIESE, Gabriel. História da Dietética: esboço de uma crítica antropológica da razão bioascética. Tese (Doutorado em Antropologia Social) - Faculdade de Filosofia, Letras e Ciências Humanas, Universidade de São Paulo, São Paulo, 2015.

RABINOW, Paul; ROSE, Nikolas. O conceito de biopoder hoje. Política e trabalho - Revista de Ciências Sociais, n. 24, p. 27-57, 2006.

ROSE, Nikolas. A política da própria vida: biomedicina, poder e subjetividade no século XXI. São Paulo: Paulus, 2013.

ROSEN, George. Da polícia médica à medicina social. São Paulo: Unesp-Hucitec; AbrasCO, 1994.

SANCHES, Antônio Nunes Ribeiro. Tratado da conservação da saúde dos povos: obra útil e, igualmente necessária aos magistrados, capitães gerais, capitães do mar e guerra, prelados, abadessas, médicos e pais de família. Paris: Bonardel e Du Beux, 1757.

SANCHES, Antônio Nunes Ribeiro. Apontamentos para estabelecer-se um Tribunal e Colégio de Medicina. Covilhã: Universidade da Beira Interior, 2003. [Edição original: 1763].

SANTOS FILHO, Lycurgo de Castro. História geral da medicina brasileira. v. 1. São Paulo: Hucitec; Edusp, 1991.

SILVA, Manoel Vieira da. Reflexões sobre alguns meios propostos por mais conducentes para melhorar o clima da cidade do Rio de Janeiro. Saúde Pública no Rio de Dom João. Rio de Janeiro: Senac; Prefeitura do Rio de Janeiro, 2008. [Edição original: 1808].

TISSOT, Samuel Auguste. Aviso ao povo acerca de sua saúde. Tomos I, II, III. Traduzido ao português e acrescentado com notas e ilustrações, e um tratado de enfermidades mais frequentes tanto internas quanto internas que não tratou Mr. Tissot em sua referida obra por Manuel Joaquim Henriques de Paiva. Lisboa: Oficina Fellipe da Silva e Azevedo, 1786. 